\title{
Management of Postintubation Tracheal Stenosis: Appropriate Indications Make Outcome Differences
}

\author{
Antoine E. Melkane ${ }^{a} \quad$ Nayla E. Matar ${ }^{a} \quad$ Amine C. Haddad ${ }^{a} \quad$ Michel N. Nassar $^{a}$ \\ Homère G. Almoutran ${ }^{\mathrm{a}}$ Ziad Rohayem ${ }^{\mathrm{a}}$ Mohammad Daher ${ }^{\mathrm{b}}$ \\ Georges Chalouhy ${ }^{b}$ George Dabar ${ }^{\text {b }}$
}

Departments of a Otolaryngology - Head and Neck Surgery, and ${ }^{b}$ Pulmonary and Critical Care Medicine, Hôtel Dieu de France Hospital, Saint Joseph University, Beirut, Lebanon

\section{Key Words}

Laryngotracheal stenosis · Tracheal stenosis • Intubation complications $\cdot$ Tracheal resection - Airway surgery •

Tracheal dilation $\cdot$ Tracheal stent $\cdot$ Argon plasma coagulation

\begin{abstract}
Background: Laryngotracheal stenosis is difficult to treat and its etiologies are multiple; nowadays, the most common ones are postintubation or posttracheostomy stenoses. $\mathbf{O b}$ jective: To provide an algorithm for the management of postintubation laryngotracheal stenoses (PILTS) based on the experience of a tertiary care referral center. Methods: A retrospective study was conducted on all patients treated for PILTS over a 10-year period. Patients were divided into a surgically and an endoscopically treated group according to predefined criteria. The characteristics of the two groups were analyzed and the outcomes compared. Results: Thirtythree consecutive patients were included in the study: 14 in the surgically treated group and 19 in the endoscopically treated group. Our candidates for airway surgery were healthy patients presenting with complex tracheal stenoses, subglottic involvement or associated tracheomalacia. The
\end{abstract}

endoscopic candidates were chronically ill patients presenting with simple, strictly tracheal stenoses not exceeding $4 \mathrm{~cm}$ in length. Stents were placed if the stenosis was associated with tracheomalacia or exceeded $2 \mathrm{~cm}$ in total length. In the surgically treated group, 2/14 patients needed more than one procedure versus $8 / 19$ patients in the endoscopically treated group. At the end of the intervention, $50 \%$ of the patients were decannulated in the surgically treated group versus $84.2 \%$ in the endoscopically treated group $(p=0.03)$. However, the decannulation rates at 6 months and the symptomatology at rest and on exertion on the last follow-up visit were comparable in the two groups. Conclusion: Our experience in the management of PILTS demonstrates that both surgery and endoscopy yield excellent functional outcomes if the treatment strategy is based on clear, predefined objective criteria.

Copyright $\odot 2010$ S. Karger AG, Basel

\section{Introduction}

Laryngotracheal stenosis is a challenging disease to manage. Its etiologies are multiple; nowadays, the most common ones are postintubation or posttracheostomy

\section{KARGER}

Fax +41613061234 E-Mail karger@karger.ch www.karger.com
(C) 2010 S. Karger AG, Basel

$0025-7931 / 10 / 0795-0395 \$ 26.00 / 0$

Accessible online at:

www.karger.com/res
George Dabar, MD

Department of Pulmonary and Critical Care Medicine, Hôtel Dieu de France Hospital PO Box 16-6830, Alfred Naccache Blvd

Beirut (Lebanon)

Tel.+961 1615 300, Fax +961 1615300 9314, E-Mail georges.dabar@usj.edu.lb 
stenoses [1]. Algorithms proposed for endoscopic management or surgical treatment are based on single-center experience and are limited by the number of patients, length of follow-up period or the absence of comparison between different treatment modalities [2-5].

Our goal was to report the long-term functional outcomes in a series of patients with postintubation laryngotracheal stenosis (PILTS) managed by a team of interventional pulmonologists and head-and-neck surgeons, and to suggest an algorithm for the management of this condition.

\section{Patients and Methods}

We retrospectively reviewed the charts of 33 consecutive patients who underwent treatment for PILTS at our institution - an academic tertiary referral medical center - between January 1998 and December 2007. These patients have not previously been reported. Our institutional internal review board approved the study and waived patient consent due to its retrospective nature; patient confidentiality was protected. Collected data included patients' demographics, presenting symptoms, indication for intubation, comorbidities and stenosis characterisitics; vocal fold mobility was studied as well. All patients were evaluated by flexible bronchoscopy or had a CT scan or both, and were treated by the same multidisciplinary team consisting of two head-and-neck surgeons and one interventional pulmonologist.

\section{Surgically Treated Group}

The surgical treatment consisted of tracheal resection with primary cricotracheal or tracheotracheal end-to-end anastomosis as initially described by Grillo [6] in 1978. Our selection criteria for the surgical group were: good health status, involvement of the subglottic region, complex or long $(>3 \mathrm{~cm})$ tracheal stenosis, and tracheomalacia. When the first tracheal ring was involved, an end-to-end cricotracheal anastomosis had to be performed instead of the usual tracheotracheal anastomosis. When the cricoid cartilage was damaged, a hyoid bone or costal cartilage graft had to be interposed through an anterior cricoid split. A posterior cricoid split was also done when needed. In patients who had long segment resections, additional suprahyoid muscle release had to be performed. Finally, concomitant tracheo-esophageal fistulas were primarily closed by means of an interposed sternocleidomastoid muscle flap. Patients with subglottic involvement had a concomitant tracheotomy done $2 \mathrm{~cm}$ below the anastomosis site. They were decannulated 7-10 days postoperatively after fiber-optic demonstration of a patent airway.

\section{Endoscopically Treated Group}

Our selection criteria for the endoscopic group were: debilitated health status, noncircumferential and strictly tracheal stenoses or stenoses not exceeding $2 \mathrm{~cm}$ in length. Stents were placed whenever a stenosis was associated with tracheomalacia or its length exceeded $2 \mathrm{~cm}$. The endoscopic treatment modalities included dilation with rigid bronchoscopes, argon plasma coagula- tion (APC) coupled with stenting (silicone or metallic), and/or mitomycin C (MMC) application. The operation was performed under general anesthesia.

Dilation was considered successful when a 10.5 -mm external diameter bronchoscope could be passed through the site.

APC equipment consisted of an APC probe, an argon gas source, and a high-frequency surgical unit (APC 300, Erbotom ICC; Erbe Elektromedizin, Tübingen, Germany). To deliver the gas, we used a flexible monopolar $1.5-\mathrm{mm}$ diameter and $150-\mathrm{cm}$ length Teflon tube, introduced through a rigid suction unit. The working parameters were $35 \mathrm{~W}$, spray pulse, pulsed mode, and $0.1 \mathrm{~s}$. The inspired oxygen concentration was maintained at $<30 \%$ throughout the procedure. The stenotic lesion was endoscopically visualized and then coagulated until satisfactory dilation of the tracheal lumen was achieved (about 8-10 mm diameter).

Stents were placed when stenoses exceeded $2 \mathrm{~cm}$ in length. Silicone stents (Dumon type; Bryancorp, Woburn, Mass., USA) were used when the stenosis was not associated with malacia in the remaining portion of the trachea and when the stent was expected to be removed. Metallic stents (Ultraflex Tracheobronchial, Microvasive Boston Scientific Corporation, Watertown, Mass., USA) were placed when the expected 5-year-survival was unlikely, and when the stenosis was associated with significant tracheomalacia.

MMC was used in 2 patients as an adjuvant treatment for airway stenosis at the dose of $0.5 \mathrm{mg} / \mathrm{ml}$, with an application time of 4 min as stated in most studies [7].

Postoperative care included antibiotics when purulent secretions were encountered, and inhaled corticosteroids (budesonide $400 \mu \mathrm{g}, 3$ times per day) when isolated dilations were performed.

\section{Outcomes}

Surgical outcomes, i.e. decannulation rates at 6 months and on the last follow-up visit, were evaluated. Dyspnea at rest and on exertion was also assessed on the last visit. No patients were lost to follow-up.

\section{Statistical Analysis}

The $\chi^{2}$ and the Wilcoxon rank sum tests were used to compare categorical and numerical variables, respectively. All statistical tests were two-tailed and were performed using SPSS software. Results were considered significant when $\mathrm{p}<0.05$.

\section{Results}

Thirty-three consecutive patients were included in the study: 14 in the surgically treated group and 19 in the endoscopically treated group.

The sex and age distributions, and the presence of comorbidities, such as diabetes, vascular disease and chronic pulmonary disease, are reported in table 1 . Comorbidities were present more frequently in the endoscopically treated group $(\mathrm{p}<0.05)$ 
All patients had histories of prolonged intubation or tracheostomy. The number of patients with histories of tracheotomy was 6/14 in the surgically treated group and $8 / 19$ in the endoscopically treated group.

The conditions leading to intubation or tracheotomy are listed in table 2.

Fifty percent of patients in the surgically treated group had subglottic stenoses as compared to $26.3 \%$ in the endoscopically treated group. All the remaining patients had strictly tracheal stenoses. The prevalence of subglottic stenoses tended to be higher in the surgical group, but the difference was not statistically significant $(\mathrm{p}=0.16)$.

In the surgical group, the majority of the stenoses ranged between 2 and $4 \mathrm{~cm}$ whereas in the endoscopic group, most of the stenoses were less than $3 \mathrm{~cm}$ in length.

A concomitant tracheo-esophageal fistula was encountered in 2 patients; those cases were referred for surgery.

Four patients (28.6\%) in the surgically treated group had histories of prior endoscopic treatment in other institutions.

\section{Surgically Treated Group}

Ten of the fourteen patients (71.4\%) with tracheal stenoses underwent resection followed by direct end-to-end tracheotracheal anastomoses; the number of the resected tracheal rings ranged between 2 and 5 . Four of the fourteen $(28.6 \%)$ patients underwent cricotracheal anastomoses for subglottic stenoses. Two of these patients presented with damage to their cricoid cartilages requiring the interposition of a costal cartilage graft through an anterior cricoid split in the first one and a posterior cricoid split in the second.

Two of the fourteen patients necessitated more than a single open surgical procedure. Patients with tracheal stenoses were immediately extubated whereas those with subglottic stenoses kept their tracheotomies for 1 week.

\section{Endoscopically Treated Group}

The endoscopically treated patients underwent variable combinations of bronchoscopic dilation, APC, stent placement and MMC application.

Eleven of the nineteen patients were managed with a single procedure: 5 underwent APC followed by bronchoscopic dilation, 4 underwent APC followed by stent placement, and 2 underwent APC followed by MMC application.

Four of the nineteen patients needed 2 procedures: 2 underwent APC followed by stent placement and 2 underwent stent replacement.

Management of Postintubation Tracheal Stenosis
Table 1. Patient characteristics

\begin{tabular}{lll}
\hline & $\begin{array}{l}\text { Surgically } \\
\text { treated } \\
\text { group }\end{array}$ & $\begin{array}{l}\text { Endoscopically } \\
\text { treated } \\
\text { group }\end{array}$ \\
\hline $\begin{array}{ll}\text { Number of patients } \\
\text { Male/female }\end{array}$ & 14 & 19 \\
Mean age, years & $9 / 5$ & $11 / 8$ \\
Comorbidities, \% & 44.2 & 57.8 \\
\hline
\end{tabular}

Table 2. Conditions leading to intubation

\begin{tabular}{lll}
\hline Conditions & $\begin{array}{l}\text { Surgically } \\
\text { treated } \\
\text { group }\end{array}$ & $\begin{array}{l}\text { Endoscopically } \\
\text { treated } \\
\text { group }\end{array}$ \\
\hline Coma & $7(50)$ & $4(21)$ \\
Cardiorespiratory arrest & $2(14.2)$ & $6(31.6)$ \\
Bilateral vocal fold paralysis & $2(14.2)$ & $0(0)$ \\
Respiratory distress & $1(7.1)$ & $5(26.3)$ \\
Cerebrovascular accident & $1(7.1)$ & $1(5.3)$ \\
Oral cavity neoplasm & $1(7.1)$ & $0(0)$ \\
Polytrauma & $0(0)$ & $1(5.3)$ \\
Septic shock & $0(0)$ & $1(5.3)$ \\
Pancreatitis & $0(0)$ & $1(5.3)$ \\
\hline
\end{tabular}

Results represent numbers and percentages (shown in parentheses).

Four of the nineteen patients needed 3 or more procedures; mainly stent replacements. Stents were indicated in 10 patients: we used silicone stents in 5 patients and metallic stents in the other 5 patients.

\section{Outcomes}

Outcomes, i.e. decannulation rates at 6 months and on the last follow-up visit, were evaluated. Dyspnea at rest and dyspnea on exertion were also assessed on the last visit. At the end of the intervention, $50 \%$ of the patients were decannulated in the surgically treated group versus $84.2 \%$ in the endoscopically treated group $(\mathrm{p}=0.03)$. However, $8 / 14$ patients in the surgically treated group had had tracheotomies prior to surgery, with 7 patients keeping them in the immediate postoperative course; in the endoscopically treated group, only $2 / 19$ patients had preoperative tracheotomies, with 1 patient keeping it after the intervention.

Respiration 2010;79:395-401 
However, the decannulation rate at 6 months was $85.7 \%$ in the surgically treated group versus $84.2 \%$ in the endoscopically treated group. At the last follow-up visit, the decannulation rate progressed to $92.8 \%$ in the surgically treated group versus $94.7 \%$ in the endoscopically treated group. $85.7 \%$ of the surgically treated patients versus $89.5 \%$ of the endoscopically treated patients were asymptomatic at rest, and 78.6\% (surgically treated group) versus $73.7 \%$ (endoscopically treated group) remained symptom free on exertion. The mean follow-up period was 18 months for both groups. All these results were not statistically different. The global survival rate at 2 years was $100 \%$ in surgically treated and $78.9 \%$ in endoscopically treated patients.

\section{Discussion}

Numerous reports agree that iatrogenic instrumentation of the trachea for nonlaryngotracheal illnesses remains the primary cause for significant laryngotracheal stenoses in our era of critical care management advances [1]. Cicatricial PILTS is defined as the progressive and permanent diminution of the laryngotracheal lumen, with replacement of normal wall tissue by fibrous tissue [3]. Overinflated $(>30 \mathrm{~mm} \mathrm{Hg})$ endotracheal tube/tracheotomy cuffs induce mucosal ischemia and subsequent chondritis, granulation tissue, and finally development of scar tissue, leading to stenosis.

The indications for different treatment modalities of symptomatic PILTS have not been clearly defined yet. Prior clinical practice dictated an attempt at dilation before proceeding to major reconstruction [8-10]. Although laryngotracheal dilation often improves airway symptoms, it represents a maintenance procedure requiring repetitive measures. Alternatively, surgical reconstructions offer the potential for immediate decannulation in a one-step procedure with higher success rates and acceptable morbidity and mortality [3].

During the 1980s and 1990s, it became apparent, notably through the works of Grillo, Pearson, and Laccourreye, that resection of laryngotracheal stenoses with primary anastomotic reconstruction could achieve decannulation rates as high as $97 \%[11,12]$. Other authors reported successful decannulation rates after segmental resection and primary anastomosis, ranging from 91 to $96 \%$ [13-15]. Rhee et al. [16] described the use of cartilage grafting in a single-stage laryngotracheal reconstruction without stenting. In their series of 15 patients, they reported 1 perioperative death, and a decannulation rate of
$100 \%$, with 3 patients requiring single procedures, and 11 patients requiring multiple procedures (ranging from 2 to 16 operations), in addition to the 8 patients who required postoperative temporary tracheotomies for airway obstruction.

Endoscopic treatment traditionally includes dilation, $\mathrm{Nd}: Y A G$ or $\mathrm{CO}_{2}$ laser-assisted excision, endoscopic stent placement and MMC application.

Stenotic lesions amenable to endoscopic management of have several features in common: (a) presence of an external cartilaginous support, (b) vertical length less than $1 \mathrm{~cm}$ (or $<3 \mathrm{~cm}$ if stenting is considered), (c) noncircumferential, and (d) strictly tracheal localization [17]. Although dilation represents a safe and well-tolerated procedure, temporary improvement is often followed by recurrences requiring repeated dilations or airway surgery. However, the development of other, more efficient endoscopic techniques has limited the need for repetitive dilations or open procedures. Among these techniques, topical MMC application, as suggested by a recent review of the literature by Warner and Brietzke [7], might improve airway surgery outcomes, but the poor quality of the studies in humans makes it difficult to draw conclusions. Laser-assisted endoscopy and stent placement have been used and reported more frequently.

In a recent study on the endoscopic management of laryngotracheal stenoses, Smith and Elstad [18] concluded that MMC may postpone the recurrence of symptomatic stenoses in the majority of patients, but does not prevent them.

The controversial background of the management of PILTS was our main motivation to perform the present investigation. In a retrospective study, Herrington et al. [5] compared open airway surgery versus dilation treatment in 127 patients treated for laryngotracheal stenoses that resulted from intubation in half the cases. Their data suggest that patients treated by primary surgery required additional interventions less often than did patients undergoing primary dilation ( 27 vs. $70 \%$ ). Furthermore, patients with PILTS seemed to be better candidates for a one-step reconstruction than patients with systemic diseases, in whom repetitive dilations were more effective. However, no specific criteria for the choice of the treatment strategy were cited in the article. In the same fashion, Mandour et al. [3] compared $\mathrm{CO}_{2}$ laser-assisted endoscopic resection with surgical reconstruction in a series of 28 patients presenting with laryngotracheal stenoses of various etiologies. They concluded that open surgery provided a higher success rate and better functional results. Their selection criteria for the endoscopic 
Fig. 1. Recommended algorithm for the management of PILTS in patients in good health. R/A = Resection and anastomosis; $\mathrm{TT}=$ tracheotracheal; $\mathrm{CT}=$ cricotracheal; $\mathrm{SHM}=$ suprahyoid muscles.

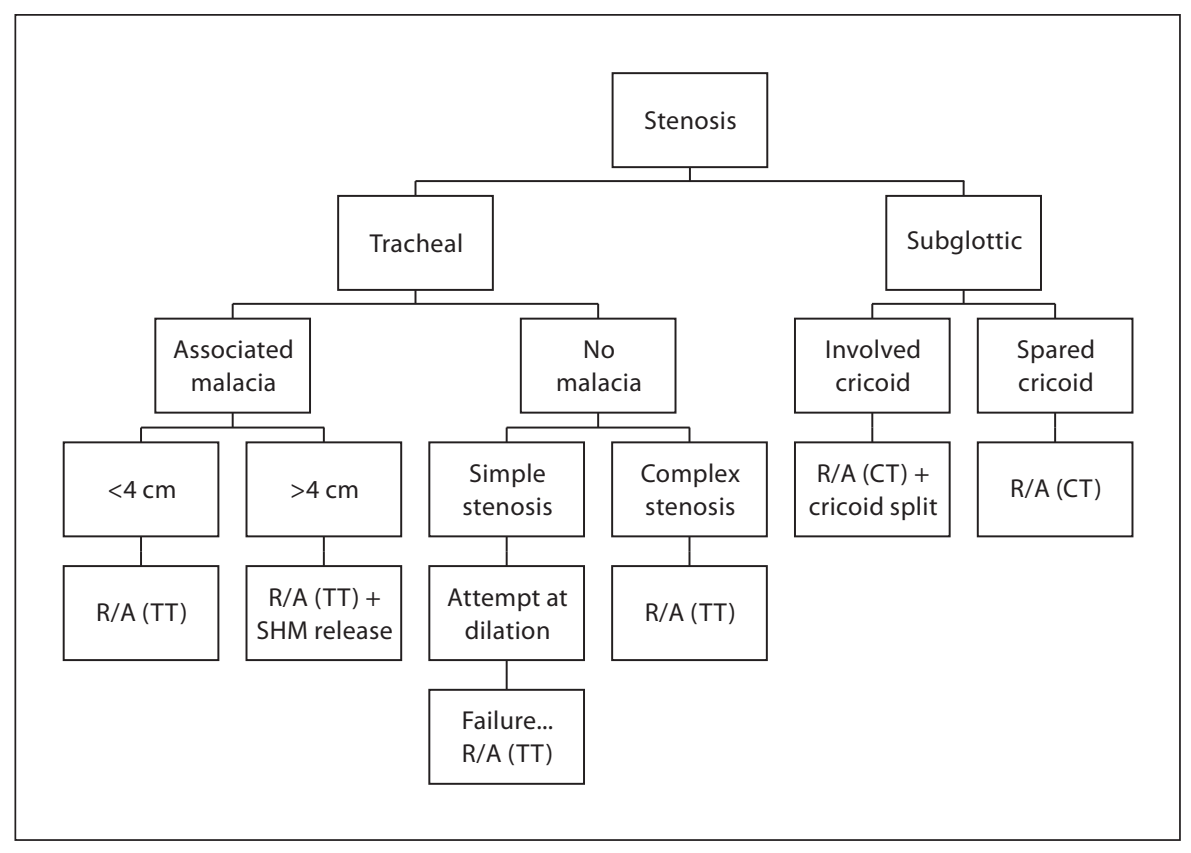

management were: multiple systemic diseases contraindicating open surgery (10 patients), personal preference (2 patients), and presence of tracheomalacia (1 patient). In their report on 46 tracheal stenoses (mainly PILTS), Cuisnier et al. [4] obtained a higher success rate with sleeve resection (91\%) compared to endoscopic treatments (79\% for tracheal stents and 50\% for iterative dilations). They concluded that sleeve resection was the gold standard treatment, and that tracheal stents (with adequate dimensions) should be considered whenever surgery is contraindicated, to avoid often inefficient iterative dilations.

In their series of 32 patients treated for chronic laryngotracheal stenoses, Massoud et al. [19] reported a higher improvement rate in the respiratory function tests in the early postoperative period in the endoscopically treated group compared to the group treated by open surgery. However, in the long term, the endoscopic results slightly deteriorated while the results in the group treated by open surgery improved. This was attributed to tissue swelling, which subsided only slowly, thus preventing immediate airway patency in the surgical group, in contrast to the immediate optimal result achieved by laser-assisted endoscopic management. However, the good results achieved by the endoscopic approach were secondarily altered by scar retraction or the formation of granulation tissue. This finding is confirmed in our study, where the immediate decannulation rate was higher in the endo-

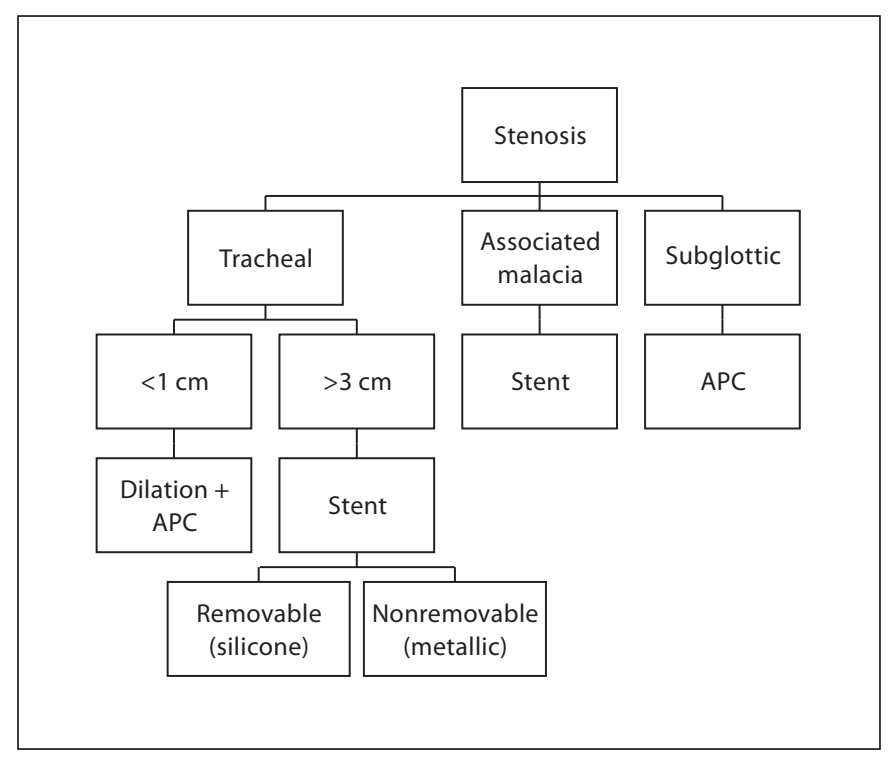

Fig. 2. Recommended algorithm for the management of PILTS in patients in poor health.

scopically treated group compared to the surgically treated group. However, this difference did not persist after 6 months.

In contrast to the aforementioned conclusions, Brichet et al. [20] consider that endobronchial dilatation by 
Nd:YAG laser or stent implantation is the optimal approach to PILTS and suggest an algorithm for its management.

In our study, the endoscopic treatment was mainly based on APC. APC has been used for open surgery for more than 15 years as well as for both laparoscopy and gastrointestinal endoscopy [21-23]. The procedure is convenient, simple to use, relatively cheap, and has an excellent safety profile. APC has also proved effective for the treatment of benign or malignant airway narrowing and posttracheal anastomosis as it allows rapid coagulation with minimal manipulation and mechanical trauma to the target tissue [24-26]. The use of this treatment modality for PILTS has only been reported in 1 case report [27].

Nouraeï et al. [28] confirmed the role of endoscopic treatment with good results at 6 months for fresh stenoses inferior to $3 \mathrm{~cm}$. Schweinfurth [29] also confirmed the role of endoscopic treatment in his series of patients with complete or circumferential short stenoses and cartilage collapse with the adjuvant use of MMC.

When comparing the endoscopic and surgical groups, we found that both strategies were equivalent in functional outcomes and need for repetitive procedures as long as strict indications were respected.

\section{Treatment Recommendations}

We propose a comprehensive combined approach for the management of PILTS patients, taking into consideration both patient and stenosis characteristics as well as the presence of tracheo-esophageal fistula (fig. 1, 2). Lund et al. [30] came to the same conclusion and proposed a multidisciplinary airway team for the management of nonmalignant airway obstruction.

\section{Study Limitations}

Our study has some limitations: it was conducted on a limited number of patients (33 patients) and our pre- and postoperative respiratory assessment lacked objective pulmonary function tests. Different treatment modalities have been used in both groups, and this is due to the retrospective nature of our work.

\section{Conclusion}

Management of PILTS remains a controversial subject. Most of the authors prefer tracheal resection with end-to-end anastomosis when feasible. Our experience in the management of PILTS demonstrates excellent functional outcomes with both surgery and endoscopy if the treatment strategy is based on clear, predefined objective criteria.

\section{References}

1 Lorenz R: Adult laryngotracheal stenosis: etiology and surgical management. Curr Opin Otolaryngol Head Neck Surg 2003;11: 467-472.

2 Sarper A, Ayten A, Eser I, et al: Tracheal stenosis after tracheostomy or intubation. Review with special regard to cause and management. Tex Heart Inst J 2005;32:154-158.

-3 Mandour M, Remacle M, Van de Heyning P, et al: Chronic subglottic and tracheal stenosis: endoscopic management vs surgical reconstruction. Eur Arch Otorhinolaryngol 2003;260:374-380.

4 Cuisnier O, Righini C, Pison C, et al: Prise en charge chirurgicale et/ou endoscopique des sténoses trachéales acquises non tumorales de l'adulte. Ann Otolaryngol Chir Cervicofac 2004;121:3-13.

5 Herrington $\mathrm{H}$, Weber S, Andersen P: Modern management of laryngotracheal stenosis. Laryngoscope 2006;116:1553-1557.

-6 Grillo HC: Surgical treatment of postintubation tracheal injuries. J Thorac Cardiovasc Surg 1979;78:860-866.

7 Warner D, Brietzke S: Mitomycin C and airway surgery: how well does it work? Otolaryngol Head Neck Surg 2008;138:700-709.
8 Valdez TA, Shapshay SM: Idiopathic subglottic stenosis revisited. Ann Otol Rhinol Laryngol 2002;111:690-695.

$\checkmark 9$ Giudice M, Piazza C, Foccoli P, et al: Idiopathic subglottic stenosis: management by endoscopic and open-neck surgery in a series of 30 patients. Eur Arch Otorhinolaryngol 2003;260:235-238.

-10 Hoffman GS, Thomas-Golbanov CK, Chan J, et al: Treatment of subglottic stenosis, due to Wegener's granulomatosis, with intralesional corticosteroids and dilation. J Rheumatol 2003;30:1017-1021.

11 Grillo HC: Primary reconstruction of airway after resection of subglottic laryngeal and upper tracheal stenosis. Ann Thorac Surg 1982;33:3-17.

12 Laccourreye O, Bransu D, Seckin S, et al: Cricotracheal anastomosis for assisted ventilation-induced stenosis. Arch Otolarygnol Head Neck Surg 1997;113:1074-1077.

13 Pena J, Cicero R, Marin J, et al: Laryngotracheal reconstruction in subglottic stenosis: an ancient problem still present. Otolaryngol Head Neck Surg 2001;125:397-400.
14 Wolf M, Shapira Y, Talmi YP, et al: Laryngotracheal anastomosis: primary and revised procedures. Laryngoscope 2001;111:622627.

15 Rea F, Callegaro D, Loy M, et al: Benign tracheal and laryngotracheal stenosis: surgical treatment and results. Eur J Cardiothorac Surg 2002;22:352-356.

16 Rhee JS, Toohill RJ: Single-stage adult laryngotracheal reconstruction without stenting. Laryngoscope 2001;111:765-768.

17 Simpson GT, Polanyi TG: History of the $\mathrm{CO}_{2}$ laser in otolaryngology surgery. Otolaryngol Clin North Am 1983;16:739-752.

18 Smith ME, Elstad M: Mitomycin C and the endoscopic treatment of laryngotracheal stenosis: are two applications better than one? Laryngoscope 2009;119:272-283.

19 Massoud A, David WM: Adult acquired laryngeal stenosis: a study of prognostic factors. J Otolaryngol 1995;24:243-247.

20 Brichet A, Verkindre C, Dupont J, et al: Multidisciplinary approach to management of postintubation tracheal stenoses. Eur Respir J 1999;13:888-893. 
21 Quinlan DM, Naslund MJ, Brendler CB: Application of argon beam coagulation in urological surgery. J Urol 1992;147:410-412.

-22 Gale P, Adeyemi B, Ferrer K, Ong A, Brill AI, Scoccia B: Histologic characteristics of laparoscopic argon beam coagulation. J Am As soc Gynecol Laparosc 1998;5:19-22.

23 Grund KE, Storek D, Farin G: Endoscopic argon plasma coagulation (APC) first clinical experiences in flexible endoscopy. Endosc Surg Allied Technol 1994;2:42-46.

24 Morice RC, Ece T, Ece F, Keus L: Endobronchial argon plasma coagulation for treatment of hemoptysis and neoplastic airway obstruction. Chest 2001;119:781-787.
25 Sato M, Terada Y, Nakagawa T, Li M, Wada $\mathrm{H}$ : Successful use of argon plasma coagulation and tranilast to treat granulation tissue obstructing the airway after tracheal anastomosis. Chest 2000;118:1829-1831.

26 Reichle G, Freitag L, Kullmann HJ, Prenzel R, Macha HN, Farin G: Argon plasma coagulation in bronchology: a new method -alternative or complementary? Pneumologie 2000;54:508-516.
27 Yasuo M, Tanabet T, Tsushima K, et al: Endobronchial argon plasma coagulation or the management of post-intubation tracheal stenosis. Respirology 2006;11:659-662.

-28 Nouraei SA, Ghufoor K, Patel A, Ferguson T, Howard DJ, Sandhu GS: Outcome of endoscopic treatment of adult postintubation tracheal stenosis. Laryngoscope 2007;117:10731079.

29 Schweinfurth JM: Endoscopic treatment of severe tracheal stenosis. Ann Otol Rhinol Laryngol 2006;115:30-34.

-30 Lund ME, Garland R, Ernst A: Airway stenting: applications and practice management considerations. Chest 2007;131:579-587. 